\title{
Unusual 18F-FDG PET-CT finding of paraneoplasic polymyositis in a patient with lung epidermoïd carcinoma
}

Salah Nabih Oueriagli, Yassir Benameur, Omar Ait Sahel, Abdelhamid Biyi, Abderrahim Doudouh Department of Nuclear Medicine, Mohammed V Military Teaching Hospital, Mohamed V University Souissi, Rabat, Morocco

[Received 28 III 2020; Accepted 8 VII 2020]

We report the case of a 67 years old male patient, followed for epidermoïd carcinoma of the right lung, and hyper-eosinophilia on peripheral blood exploration. 18F-FDG positron emission tomography-computed tomography (18F-FDG PET-CT) performed for initial extension assessment showed, in addition to the intense hypermetabolism in the right upper pulmonary lobe related to the primary tumor and the mediastinal lymph node involvement (Fig. 1A), an unusually intense muscular hypermatbolism
A

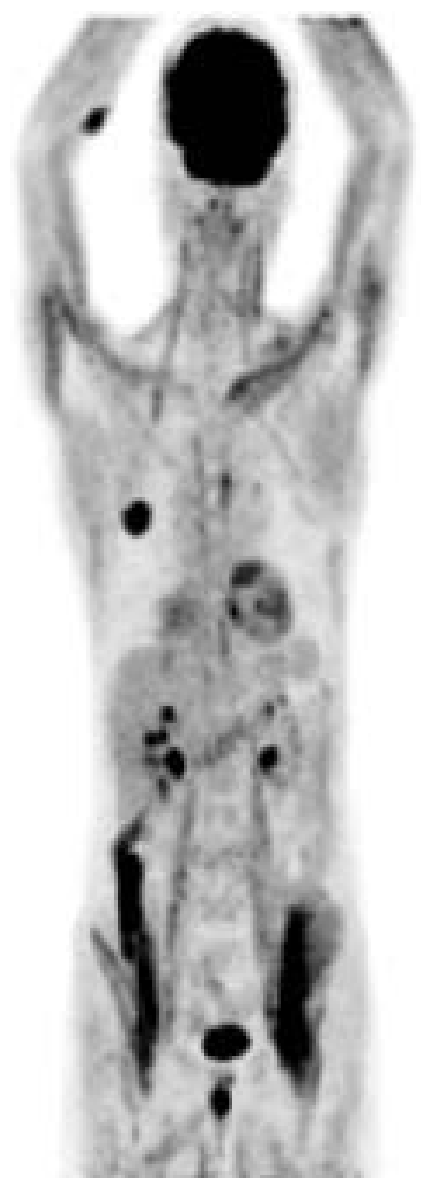

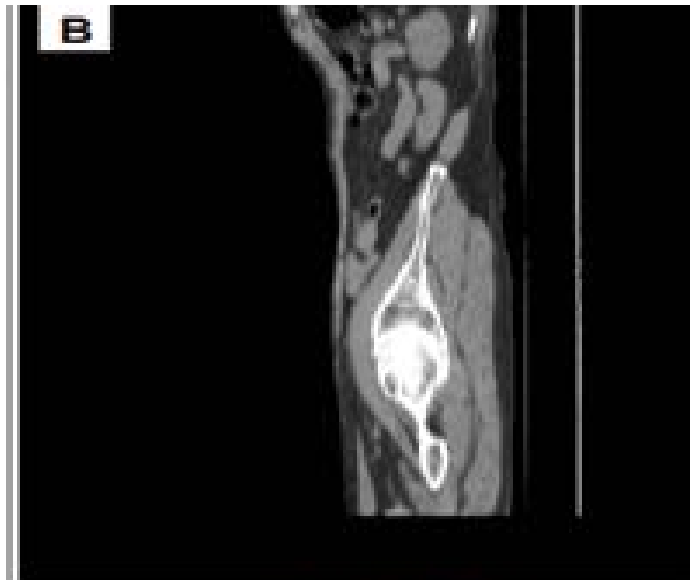

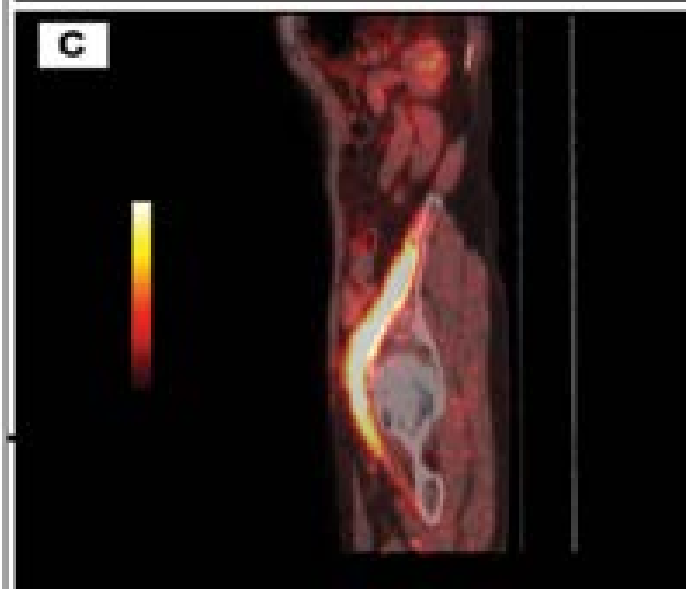

Figure 1. A. Maximum intensity projection PET image revealing intense hypermetabolism in the right upper pulmonary lobe related to the primary tumor associated to mediastinal lymph node involvement with unusual intense hypermatbolism interesting long muscles of the neck, sterno-cleidomastoid muscles, para-vertebral, iliac and ilio-psoas muscles. B. Whole body CT image and (C) 18F-FDG PET-CT fusion image in sagittal sections showing intense and symmetric hypermetabolism in ilio-psoas muscles

Correspondence to: Oueriagli Nabih Salah, Department of Nuclear Medicine, Mohammed V Military Teaching Hospital, BP 1018, Rabat, Morocco phone: +212662101402

e-mail: salah.nabihoueriagli@gmail.com 


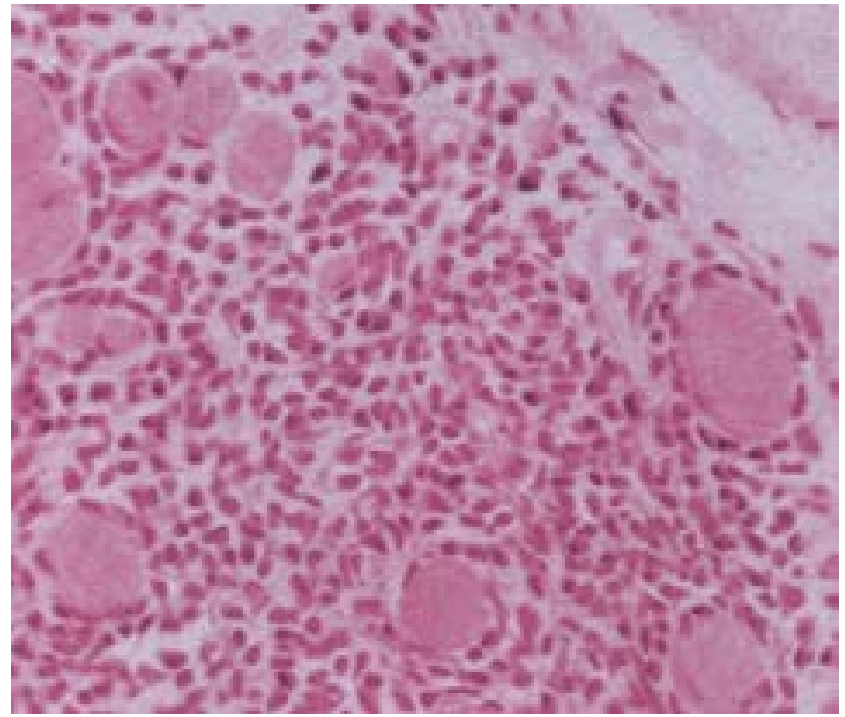

Figure 2: Biopsy of the right ilio-psoas muscle showing myofiber degeneration with predominant inflammatory cell (CD8+ T lymphocyte) compatible with polymyositis

interesting bilaterally and symmetrically long muscles of the neck, sterno-cleido-mastoid muscles, para-vertebral, iliac and ilio-psoas muscles (Fig. 1B and 1C).

Biopsy of the right ilio-psoas muscle reveals evidence of myofiber degeneration and regeneration with lymphocytes invading non-necrotic myofibers, predominant inflammatory cell (CD8+ T lymphocyte) compatible with paraneoplasic polymyositis (Fig. 2). Serum CK (creatine kinase), aldolase and sedimentation rate levels were abnormally very high.

Our patient was put under corticotherapy with good clinical, biological and radiological evolution, even on 18F-FDG PET-CT.

In our knowledge, a link between paraneoplasic polymyositis and cancer has never been clearly defined [1-2], and its clinical expression does not differ from idiopathic polymyositis [3]. Clinicopathologic diagnosis is based on histology, electromyographic data, high-level serum of muscular enzymes (creatine kinase, aldolase), and also an elevated sedimentation rate [4]. This group of patients can be treated by corticotherapy or immunomodulators, and also by physiotherapy [5].

\section{References}

1. Brown $\mathrm{H}$, Steven M. Myositis and malignancy: is there a true association? Hosp Med. 1999; 60(1): 51-53, doi: 10.12968/hosp.1999.60.1.1026, indexed in Pubmed: 10197100.

2. Hill CL, Zhang Y, Sigurgeirsson B, et al. Frequency of specific cancer types in dermatomyositis and polymyositis: a population-based study. Lancet. 2001; 357(9250): 96-100, doi: 10.1016/S0140-6736(00)03540-6, indexed in Pubmed: 11197446.

3. Dubas F. Syndromes paranéoplasiques. Ed techniques. Encycl Med Chir. 1985; 17162(A): 10.

4. Troyanov Y, Targoff IN, Tremblay JL, et al. Novel classification of idiopathic inflammatory myopathies based on overlap syndrome features and autoantibodies: analysis of 100 French Canadian patients. Medicine (Baltimore). 2005; 84(4): 231-249, doi: 10.1097/01.md.0000173991.74008.b0, indexed in Pubmed: 16010208.

5. Dalakas MC. Polymyositis and dermatomyositis. Lancet. 2003; 362: 971-82. 